\title{
Use of autogenous platelet rich plasma and 3D collagen matrix Fibromatrix for soft tissue regeneration in the treatment of Miller Class I gingival recessions
}

\author{
Rushana Farkhshatova ${ }^{1, *}$, Larisa Gerasimova ${ }^{1}$, and Milyausha Kabirova ${ }^{1}$ \\ ${ }^{1}$ Federal State Budgetary Educational Institution of Higher Education "Bashkir State Medical \\ University" Ministry of Health of the Russian Federation, Department of Therapeutic Dentistry with a \\ postgraduate course, 450008, Ufa, Russia
}

\begin{abstract}
Background: Evaluation of the effectiveness of the integrated use of autogenous platelet plasma and 3D collagen matrix Fibromatrix for the regeneration of soft tissues of the oral cavity in the surgical treatment of Miller Class I gingival recession. Materials and Method: 25 patients were examined and treated. All patients underwent surgical treatment of gingival recession using two-layer techniques of eliminating gingival recession with «3D collagen matrix FibroMATRIX» for the regeneration of soft tissues of the oral cavity and autologous platelet plasma. In all cases, the rehydration of the collagen matrix was carried out in autogenous platelet plasma for 2 minutes. The result was evaluated after $7^{\text {th }}$ day, $14^{\text {th }}$ day, 1 and 3 months. Statistical processing of the studies was carried out in GraphPadPrism v.6.0, using the t-test, Mann-Whitney. Differences were considered significant at $\mathrm{p}<0.05$. Results: Assessment of gingival recession closure and its significant $(\mathrm{p}<0.05)$ increase, corresponding to $85 \%$ efficiency after treatment in both groups of patients, no significant differences were found in both groups. The best clinical results were achieved in eliminating gingival recessions in the anterior maxilla, showing its $100 \%$ efficiency.

Conclusions: The combined use of autogenous platelet plasma and 3D collagen matrix Fibromatrix for the regeneration of soft tissues of the oral cavity is an effective method for treating Miller Class I gingival recession.
\end{abstract}

\section{Introduction}

An urgent problem in modern dental practice is gingival recession. According to World Health Organization (2012), periodontal diseases are found in $65-98 \%$ of people aged $35-45$ years. According to world statistics, the prevalence of gingival recession ranges from $23 \%$ to $99.3 \%$ (Rateitschak K. et al., 1986; Hamadeeva A.M., 1999; Smirnova S.S., 2010;

\footnotetext{
* Corresponding author: rushana1189@mail.ru
} 
Dominiak M. et al., 2014). According to some authors, the intensity and prevalence of gingival recession are in direct ration with age and reache $99.7 \%$ in the adult population [1].

Gingival recession is characterized as a non-inflammatory apical displacement of the gingival margin from its normal position with exposure of the root surface [2]. A marginal gum is lost in the vestibular and oral projections, which is keratinized attached soft tissue of the oral cavity as a result of gingival recession [3].

There are several classifications of gingival recessions, proposed by various authors in the world. The most widely used classification is Miller's (1985), in which the gingival recession is divided into 4 classes, depending on the position of the apical edge of the free gum relative to the mucogingival border and the preservation of the alveolar interdental bone septa [4]. Success (complete elimination of gingival recession) is predictable and possible in the early stages of the disease, mostly with recessions of the I - II class according to Miller, treatment is unpromising in recessions of the III and IV classes [3].

There are various methods of gingival recession treatment including conservative treatment and surgical treatment. Non-surgical treatment methods exist and are successfully used, however, they are not a full-fledged alternative to surgical intervention, since the result is often not stable [5]. Thus, surgical treatment is the most predicted type of treatment, leading to a persistent increase in gingival volume, and is also an etiopathogenetic treatment, since not only the aesthetic deficiency and hypersensitivity of the tooth are eliminated, but also part of the etiological factors, significantly reducing the risk of root caries and tooth loss [6].

A sufficient amount of keratinized gum tissue is an important factor for the stability of the periodontal tissue complex [7]. Free connective tissue transplant (CCT) is recognized as the "gold standard" and used to increase the area of keratinized attached gums during gingival recession [8]. Nevertheless, many patients do not agree on additional surgical procedures associated with operations on their own tissues [9]. In addition, these methods have a number of disadvantages, one of which is the presence of an additional surgical field, the risk of complications associated with autograft removal, bleeding, pain due to taking the patient's own tissue and its limited amount. [10]. Therefore, it is extremely urgent to search for types of surgical treatment using alternative methods of using autologous transplants nowdays.

There are many transplantation materials for the replacement of soft tissue defects in periodontal disease on the world market. An alternative to using autografts is the use of xenogenic collagen matrices. Such materials have a number of advantages: it is available in unlimited quantities, integrate well into soft tissues, and reduces the risk of complications, associated with the presence of an additional surgical field during autograft sampling [11].

To date, a new material has been developed and registered in the Russian Federation “3D Collagen Matrix FibroMATRIX” (Reg. L. RZN№2019 / 8367 dated 20/05/2019). FibroMATRIX is a xenogenic 3D collagen matrix for the regeneration of soft tissues of the oral cavity. This collagen matrix is manufactured using a unique, patented technology (RF Patent No. 2683328), which allows you to obtain a product of the required thickness thoroughly cleaned from immune agents. In the course of preclinical laboratory studies, this material showed its effectiveness and cytotoxicity in relation to proliferation of cell cultures in vitro [12]. Animal experiments have proven biocompatibility and safety.

Together with the use of medications that affect the regeneration of soft tissues, the use of collagen cell-free matrices can significantly improve the restoration of periodontal tissue microcirculation after complex treatment of gingival recession [13]. The use of platelet-rich autologous plasma allows accelerating the natural mechanisms of recovery, thanks to the growth factors contained in platelets, which control the natural mechanisms of tissue regeneration [14].

Therefore, the complex use of autogenous platelet plasma and the " $3 \mathrm{D}$ collagen matrix 
FibroMATRIX" for the regeneration of soft tissues of the oral cavity for gingival recession treatment is relevant in clinical dental practice.

\section{Purpose of the study}

Evaluation of the effictiveness of the complex use of autogenous platelet plasma and 3D collagen matrix Fibromatrix for soft tissues regeneration of the oral cavity in the surgical treatment of Miller Class I gingival recessions (ICD-10 K 06.0).

\section{Materials and Methods}

To achieve the goal of the study, we have examined and treated patients who applied to the Department of Therapeutic Dentistry with a postgraduate course at the Bashkir State Medical University in Ufa and to the dental clinic Dental Studio LLC Dina Medservice in Ufa from 2019-2020.

The object of the study was 25 patients $(73.4 \%$ women and $26.6 \%$ men) aged $20-45$ years old, with a diagnosis of Miller Class I gingival recession (ICD-10 K 06.0).

The study included only patients diagnosed with Miller Class I gingival recession (ICD$10 \mathrm{~K} 06.0$ ) aged 20-45, who considered themselves somatically healthy, with no allergic history, who gave written informed consent on the materials and methods of the study.

Comprehensive dental examination of patients was carried out according to the generally accepted standard technique, including: a survey, external examination, examination of the patient's oral cavity. The survey included patient complaints, a history of the development of this disease. In addition to the standard protocol for dental examination, a special questionnaire was conducted for patients, taking into account the technique of home hygiene of the patient's oral cavity; methods, frequency and the time of brushing; bad habits of the patient, including smoking, wearing an oral piercing, etc. Clinical dental examination included data on the height and width, the prevalence of gingival recession, the width of the keratinized gingiva in the gingival recession area, the presence of mucous cords, abnormalities of the frenulum of the lips, etc. To evaluate the metric parameters, a graduated periodontal probe (HLW, Germany) was used.

Assessment of the hygienic and periodontological status of patients was determined using the following indices: CPE, simplified hygiene index OHI-S (J.C. Green, J.R. Vermillion, 1964), interdental papilla bleeding index (PBI - papilla bleeding index; Saxer, Mühlemann, 1975). The recession class was determined using Miller's classification (P.D. Miller, 1985). Surgical interventions were performed at OHI-S $<1.7$ and PBI $<5 \%$, which indicated the absence of clinically significant inflammation of the periodontal tissues and, as a result, the high collagen content in the own soft tissues of the oral cavity.

The thickness of the gum and its biotype are estimated. The gum biotype was determined using X-ray examination by the method of computed tomography, using a technique specially developed by us to conduct this method to visualize the thickness of the attached keratinized gingiva. When registering gum thickness less than $1.0 \mathrm{~mm}$, the biotype was considered thin, with $1 \mathrm{~mm}$ or more the biotype was considered thick [15].

To assess the condition of bone tissue, an X-ray diffraction study was performed by the method of computed tomography (Vatech, South Korea). The presence of destruction of bone structures, the presence or absence of heigh loss of the bone interdental septas, the integrity of the cortical vestibular plate in the area of gingival recessions were evaluated [16].

All patients were consulted on techniques and methods for conducting oral hygiene at home. At the same time, attention was paid to performing daily hygiene procedures, the 
duration of toothbrushing, etc. Patients underwent an individual selection of products for home oral care, training in the method of brushing according to Stilman.

Before surgical treatment, no less than 48 hours before surgery, all patients underwent comprehensive professional oral hygiene (Scaling \& Root Planing).

All patients (100\%) underwent surgical treatment of gingival recession using two-layer methods for eliminating multiple and single recessions using the "FibroMATRIX 3D collagen matrix" (Cardioplant, Russia) for the regeneration of soft tissues of the oral cavity and autologous platelet plasma.

Autogenous platelet rich plasma was prepared as follows: immediately before the operation, blood was taken from the patient's ulnar vein, in accordance with the technology for performing simple medical services of invasive interventions (GOST R 52623.4-2015). A sterile disposable system (Becton Dickinson \& Company, USA) was used for blood sampling. Blood was collected in a sterile tube and centrifuged for 5 minutes. The obtained autologous platelet rich plasma was used during the operation for rehydration under sterile conditions of the used 3D collagen matrix Fibromatrix (Cardioplant, Russia) for 2 minutes.

Surgical intervention included various techniques. Patients were divided into 2 groups, depending on the indications.

If abrasive/carious cervical tooth defects in the recession area, the recession height is more than $3 \mathrm{~mm}$ and the area of the attached keratinized gums is more apical than the recession less than $3 \mathrm{~mm}$ were found, patients underwent surgical treatment using the modified rotated coronal displaced flap method (J. Zuckeli, 2000).

In case of a gingival recession of not more than $3 \mathrm{~mm}$, the width of the zone of attached keratinized gums more than $3 \mathrm{~mm}$ apical to the gingival recession, in case of single recessions, patients underwent surgical treatment using a modified tunnel technique (O. Zur, M. Hürzeller, 2012).

The first group included 12 patients ( 8 women and 4 men) with a diagnosis of ICD-10 K06.0 "Gingival Recession", class I, according to Miller. All patients were given postoperative recommendations according to the standard protocol. Sutures were removed on day 14. Postoperative examination was performed on 7, 14 days, 1 month after surgery. The treatment outcome was evaluated after 1 month.

The second group, which included 13 patients (10 women and 3 men) with a diagnosis of ICD-10 c.06.0 "Gingival Recession", class I according to Miller, underwent a modified tunnel technique for surgical treatment. All patients were given postoperative recommendations according to the standard protocol. Postoperative examination was performed on 7, 14 days. Sutures were removed on day 14. The result was evaluated after 1 and 3 months. Monitoring of patients continued up to 3 months after the operation.

All surgical manipulations were carried out under visual control; during each operation, a photographic protocol was performed in macro mode: Canon 550D camera (Canon, Japan), Canon EF-S 60mm f / 2.8 Macro USM, Canon Macro Ring Lite MR-14 EX.

The criteria for the effectiveness of the surgical intervention included the following: the percentage of increasing in the area of attached keratinized gums, absence of color and texture differences, percentage elimination of gingival recession $(100 \%$ corresponded to restoration of the free gingival margin to the cement-enamel border of the tooth), absence of pockets during probing, elimination of increased sensitivity, patient satisfaction with the aesthetic result.

The following was evaluated while examinate:

1. The presence of swelling of the soft tissues of the oral cavity according to a threepoint system ( 0 - absence of edema; 1 - mild edema; 2 - severe edema).

2 . The presence of fibrin plaque and the consistency of sutures according to a threepoint system $(0-$ absence of fibrin along the cut line, sutures are consistent; 1 - slight 
fibrinous plaque along the cut line, sutures are consistent; 2 - fibrin covers the cut line, sutures are not consistent).

3. Pain on a 4-point scale ( 0 - pain after the intervention was absent, no analgesics were required; 1 - slight pain, analgesics - total dose up to $300 \mathrm{mg} ; 2$ - moderate pain, analgesics - total dose up to $1000 \mathrm{mg} ; 3$ - severe pain, analgesic intake - total dose of more than 1000 $\mathrm{mg})$.

Statistical processing of the studies was carried out in the GraphPadPrism v.6.0 for Windows program of the Microsoft Office system using the t-test, Mann-Whitney. Differences were considered significant at $\mathrm{p}<0.05$.

\section{Clinical example No. 1}

Patient D., female, 31 years old.

Diagnosis: K06.0 Gingival recession, Miller's class I. Multiple gingival recessions of the region of 14-11 teeth from 1-4mm (Fig.1). The width of the keratinized gums over the recession in the 13th tooth region is $2.5 \mathrm{~mm}$. Gingival papillae are normal. Orthopedic treatment is planned. To maximize the elimination of resident and transient microflora, a preoperative treatment of the oral cavity with a $0.12 \%$ chlorhexidine solution was performed for 1 minute.

Under-the-forrow and paramarginal oblique incisions for forming surgical papillae in the coronal portion of the flap were done under infiltration anesthesia Sol. Ultracaini D - S $1,7 \mathrm{ml}$, with scalpel No.15C (Figure 2).

Then, an envelope combined mucosal flap was formed in the area of surgical papillae (using the sharp method using a scalpel No.15C) and a full-layer one in the apical part and along the recession border (using the blunt method using a raspator (Hu-Friedy, USA)) (Fig.3). Then, at the base of the full-layer flap, a laxative periosteum incision was made, and $3 \mathrm{~mm}$ more apical cleavage was performed, forming a mucous flap.

The exposed surfaces of the roots of the teeth were carefully processed to the height of the loss of clinical attachment in 4 stages:

1. ultrasonic treatment

2. the tool machining treatment using the Gracey's the Mini-'em Five curettes (HuFriedy, USA)

3. polishing and smoothing the surface of the roots of the teeth using periodontological burs of RA (Komet, Russia).

4. drug treatment with the application of lincomycin hydrochloride $30 \mathrm{mg}$. per ml. for 2 minutes.

Then we performed the epithelialization of the anatomical papillae with a scalpel No.15C (Fig. 4). The "FibroMATRIX collagen 3D matrix" (Cardioplant, Russia) was adapted to the required size, rehydrated in an autogenous platelet rich plasma for 2 minutes (Fig. 5) and fixed with resorbable Vicryl 4.0 filament (Ethicon Endo-Surgery, USA) with interrupted sutures in the area of anatomical gingival papillae excretion of nodes orally (Fig. 6,7). A cover envelope flap was placed on top of the FibroMATRIX collagen 3D matrix (Cardioplant, Russia), displaced as coronally as possible, completely covering the gingival recessions to the CES, and fixed with Supramid 5.0 monofilament thread (Resorba, Russia) with double entwined and interrupted sutures (Fig. 8). Drug treatment was carried out with a $0.12 \%$ solution of chlorhexidine in the area of postoperative sutures. Removing sutures ia planned after 14 days. After the operation, the closure of exposed surfaces and the complete elimination of gingival recessions are determined. The soft tissues are stable at follo-up examination after 1 month (Fig. 9). 


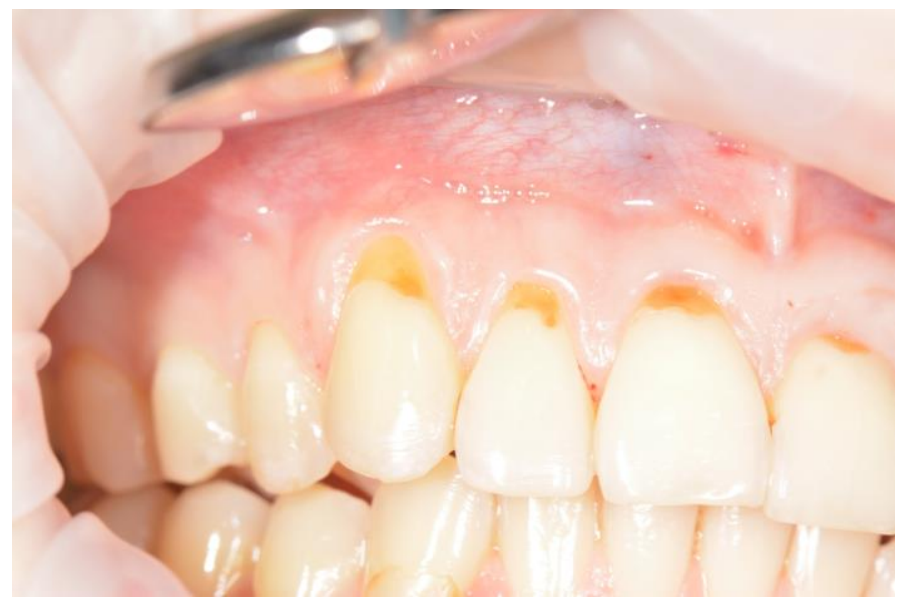

Fig. 1. Multiple Miller Class I gingival recessions in the 14-11 teeth area

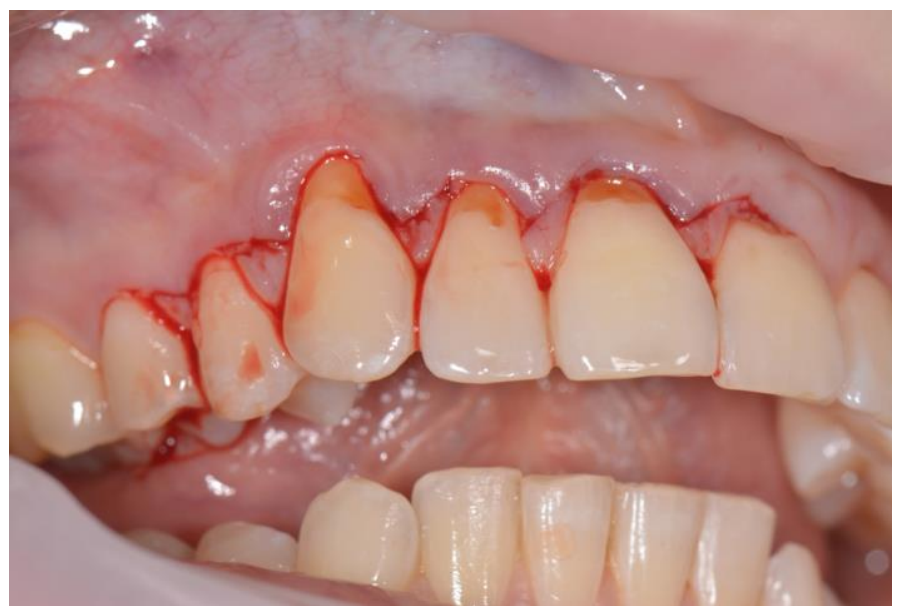

Fig. 2. Section design

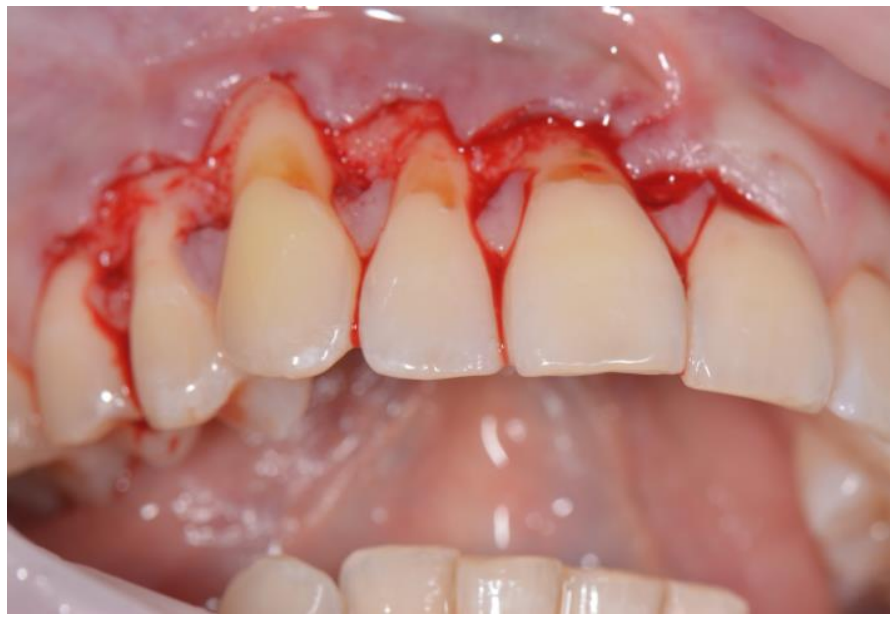

Fig. 3. The formation of the envelope combined flap 


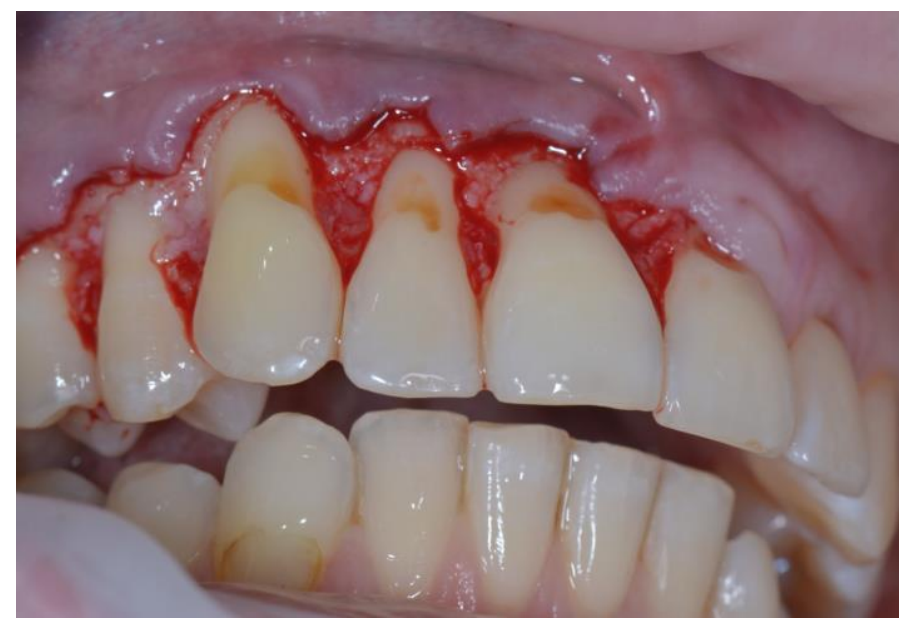

Fig. 4. De-epithelialization of the papillae after clining of the roots of the teeth

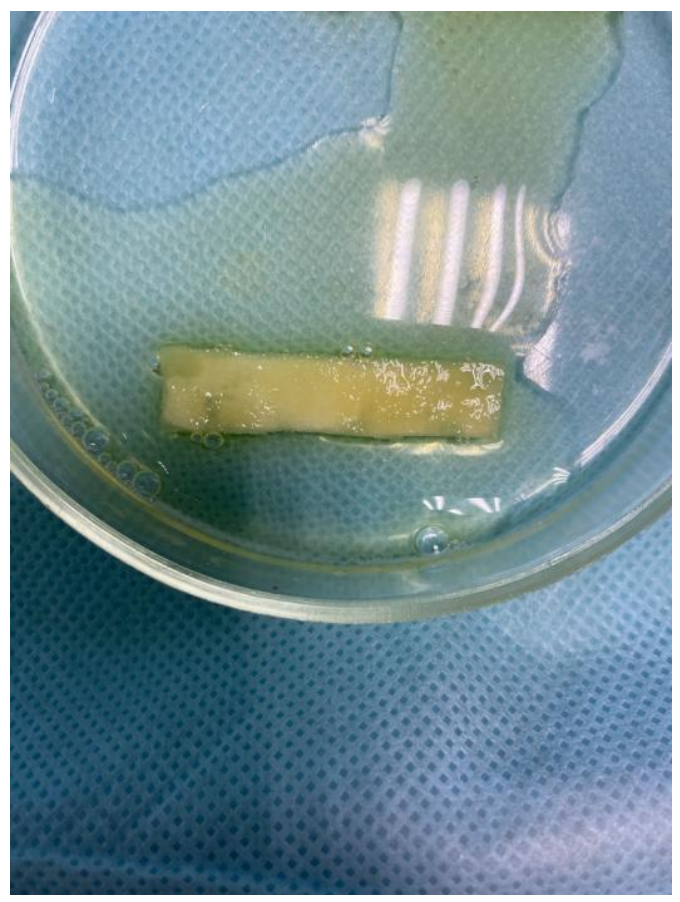

Fig. 5. Rehydration of the collagen matrix in autogenous platelet rich plasma 


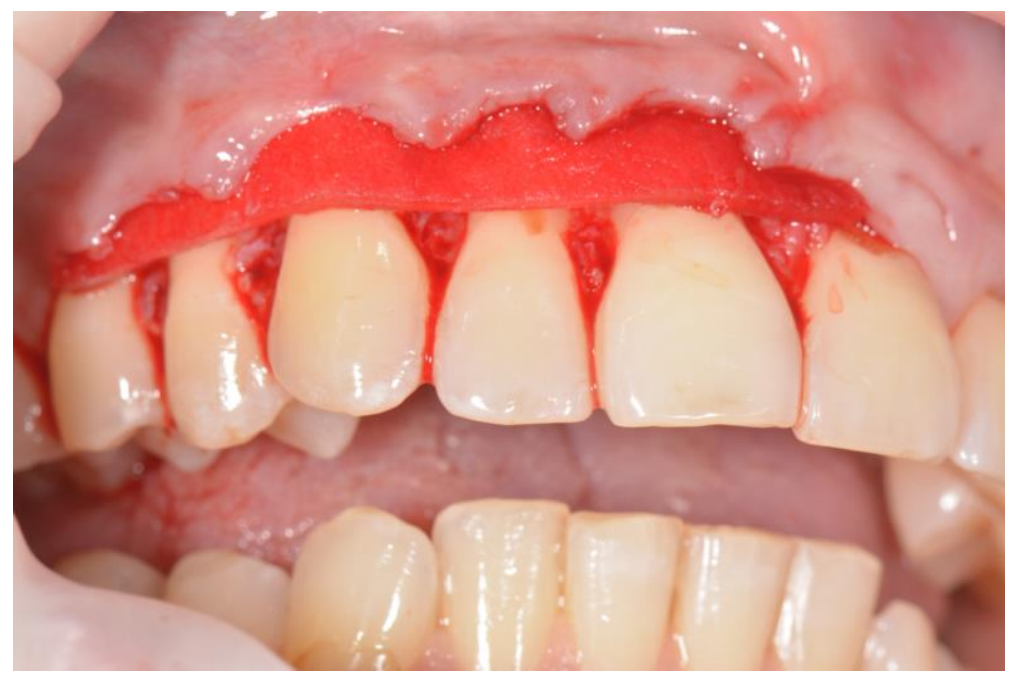

Fig. 6. Collagen matrix laid in the formed "envelope box"

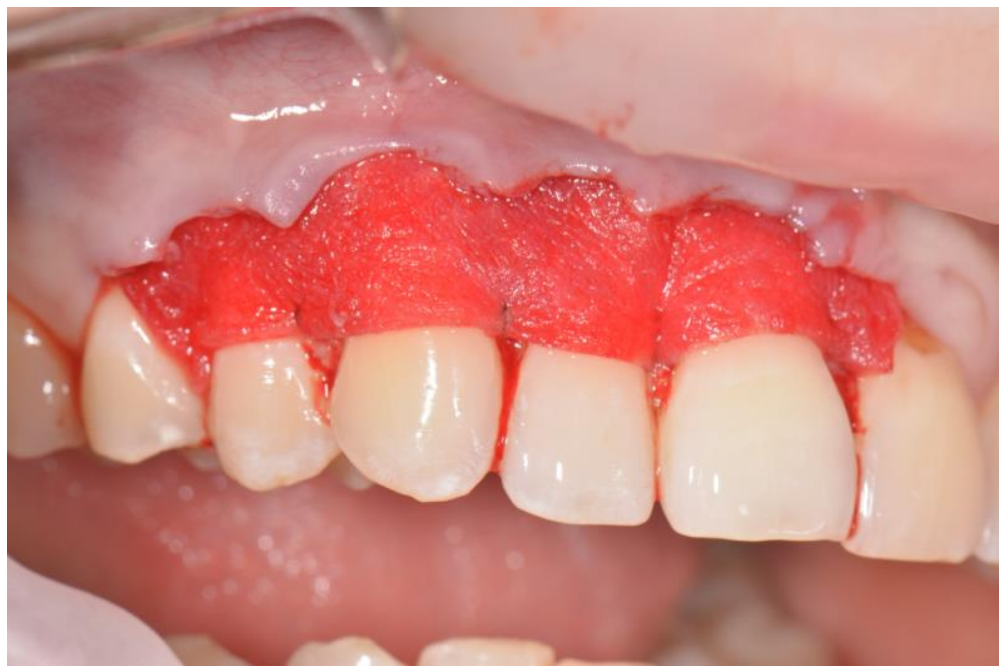

Fig. 7. Collagen matrix fixed with nodal sutures 


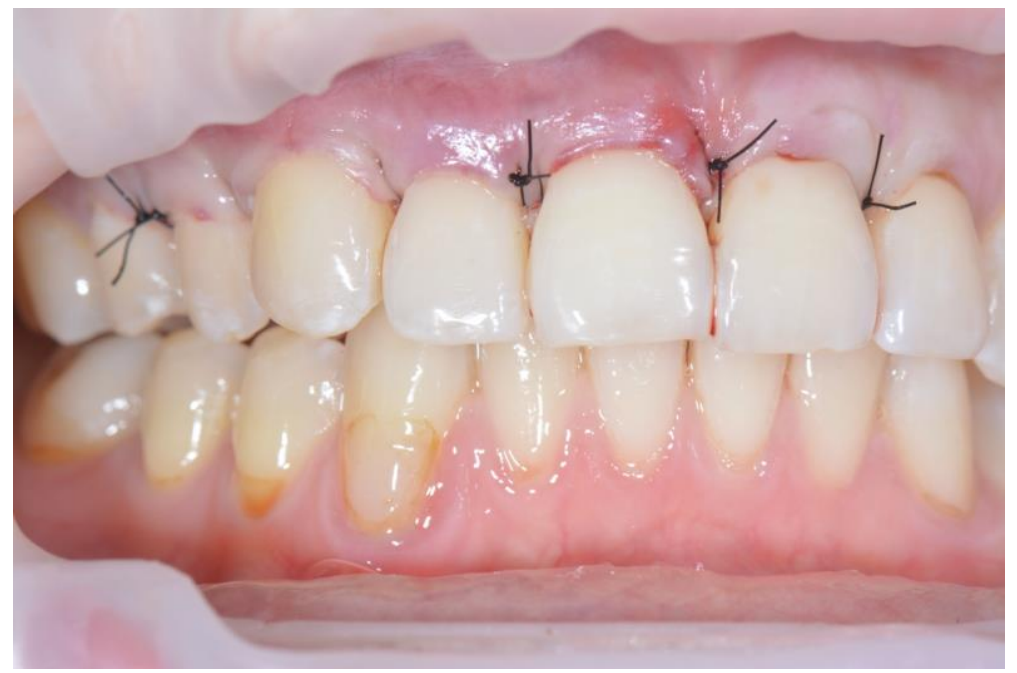

Fig. 8. View of the surgical wound after suturing

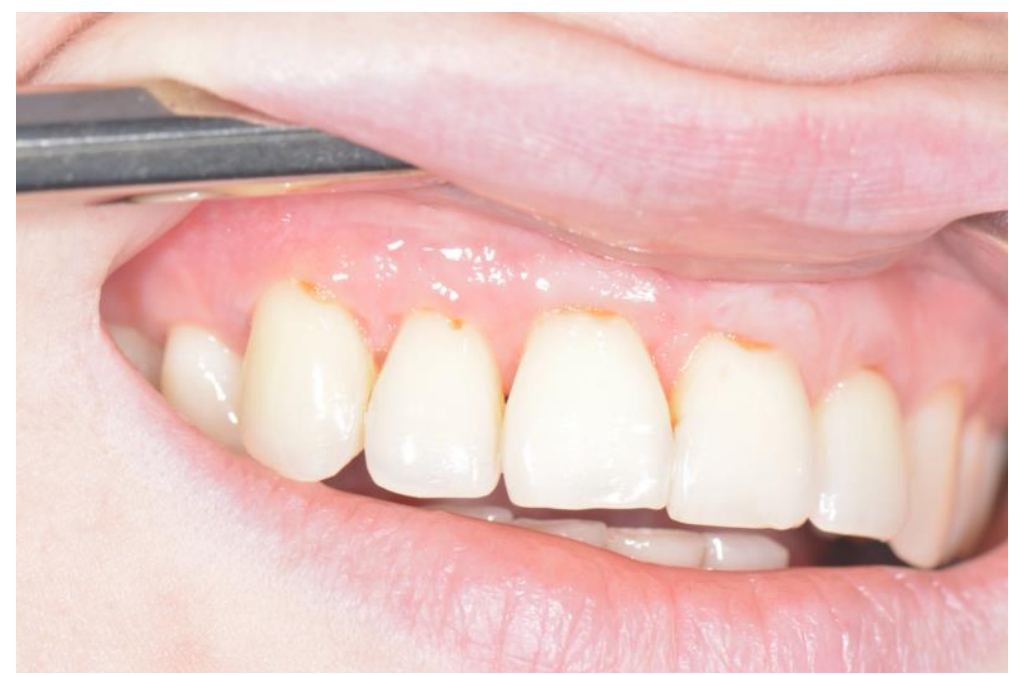

Fig. 9. Result in 1 month after the surgery

\section{Clinical example No. 2.}

Patient G., female, 26 years old.

Diagnosis: c.06.01 Gingival recession, Miller's class I. Multiple gingival recessions in the area of 22-25 teeth from 1 to $3 \mathrm{~mm}$ (Fig. 10). The width of the keratinized gums is more apical than recessions more than $3 \mathrm{~mm}$. The gum biotype is thick, the gingival papillae is normal. Orthodontic treatment is planned.

Preoperative treatment of the oral cavity was performed with a $0.12 \%$ chlorhexidine solution for 1 minute. Under nnfiltration anesthesia Sol. Ultracaini D - S $1.7 \mathrm{ml}$ performed an intra- fissure incision using a microsurgical scalpel (MANI, Japan). The surface treatment of the roots of the teeth was carried out in 4 stages (see above). 
The tunnel raspator (Hu - Friedy, USA) exfoliated the mucous membrane of the split flap and prepared the tunnel bed (Fig. 11). The collagen 3D matrix FibroMATRIX (Cardioplant, Russia) was rehydrated in an autogenous platelet rich plasma for 2 minutes (Fig. 12), adapted in size (Fig. 13) and introduced into the tunnel bed using guides, positioning joints Prolene 5.0 (Ethicon Endo-Surgery, USA) (Fig. 14).

The mucous membrane is fixed coronally, completely covering the gingival recession to the enamel border. Wound closure was performed using Prolene 5.0 double-wound stitches (Ethicon Endo-Surgery, USA) (Fig. 15). Postoperative drug treatment was performed with a $0.12 \%$ chlorhexidine solution. Removing sutures is planned after 14 days. There is a complete elimination of gingival recessions in the area of 22-24 teeth (Fig. 16). The soft tissues are stable at the control examination after 3 months (Fig. 17).

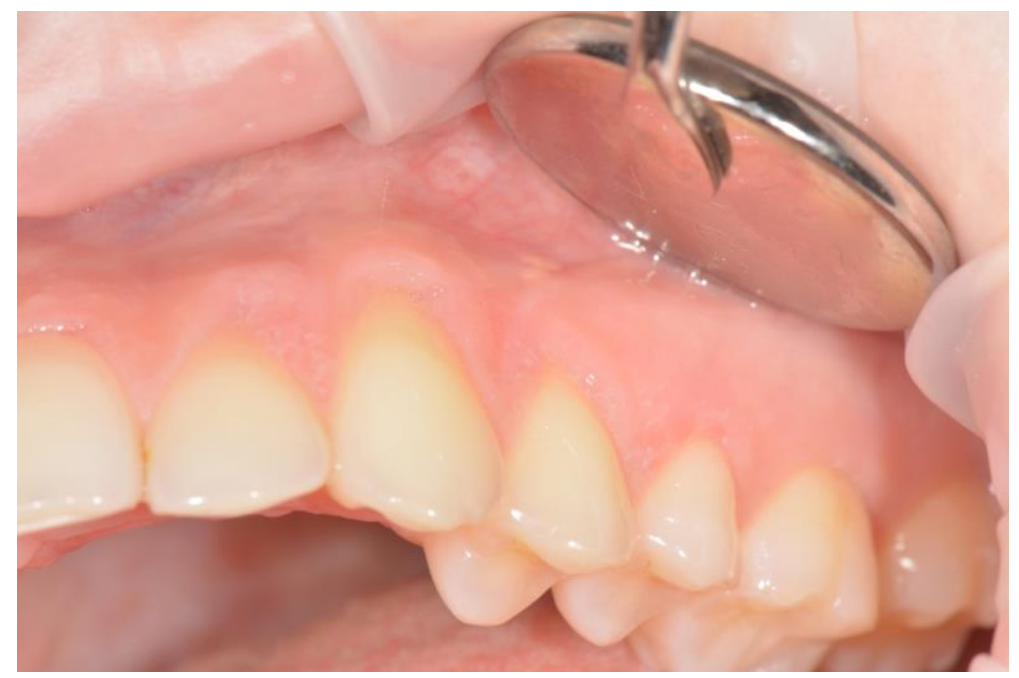

Fig. 10. Multiple Miller Class I gingival recessions in the area of 21-24 teeth

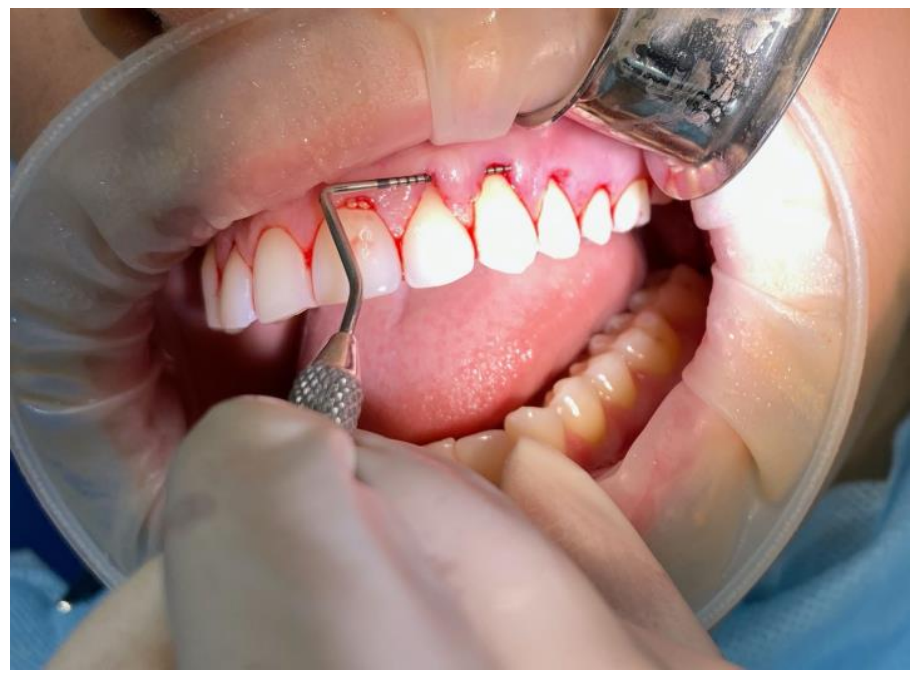

Fig. 11. View of the formed "tunnel" in the area of 21-24 teeth 


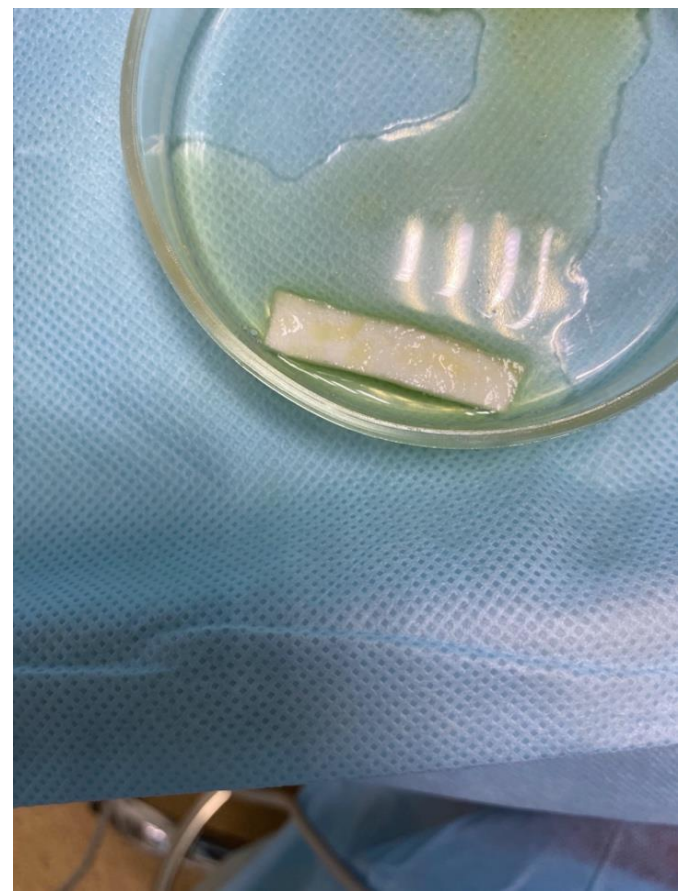

Fig. 12. Rehydration of the collagen matrix in autogenous platelet rich plasma

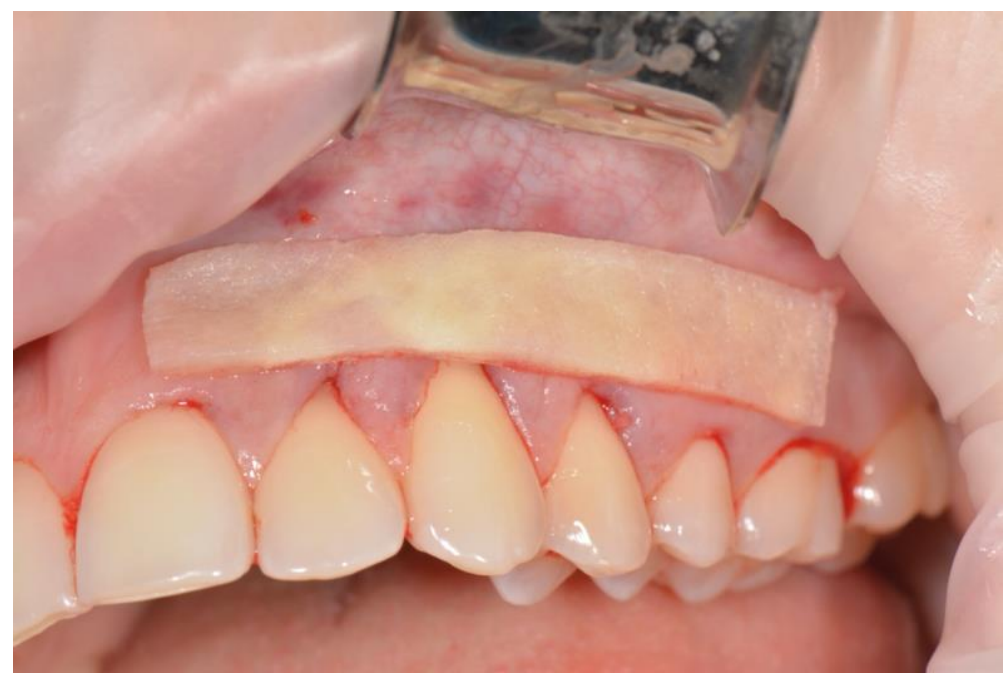

Fig. 13. Adaptation of the collagen matrix in accordance with the required dimensions 


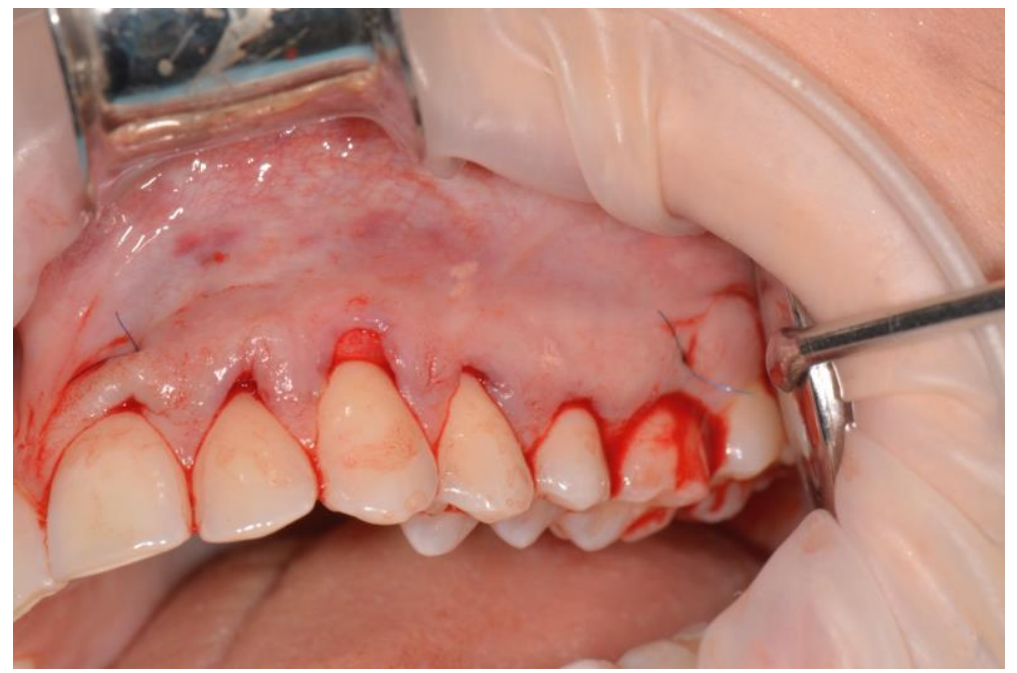

Fig. 14. The collagen matrix is installed in the "tunnel" and fixed with interrupted sutures

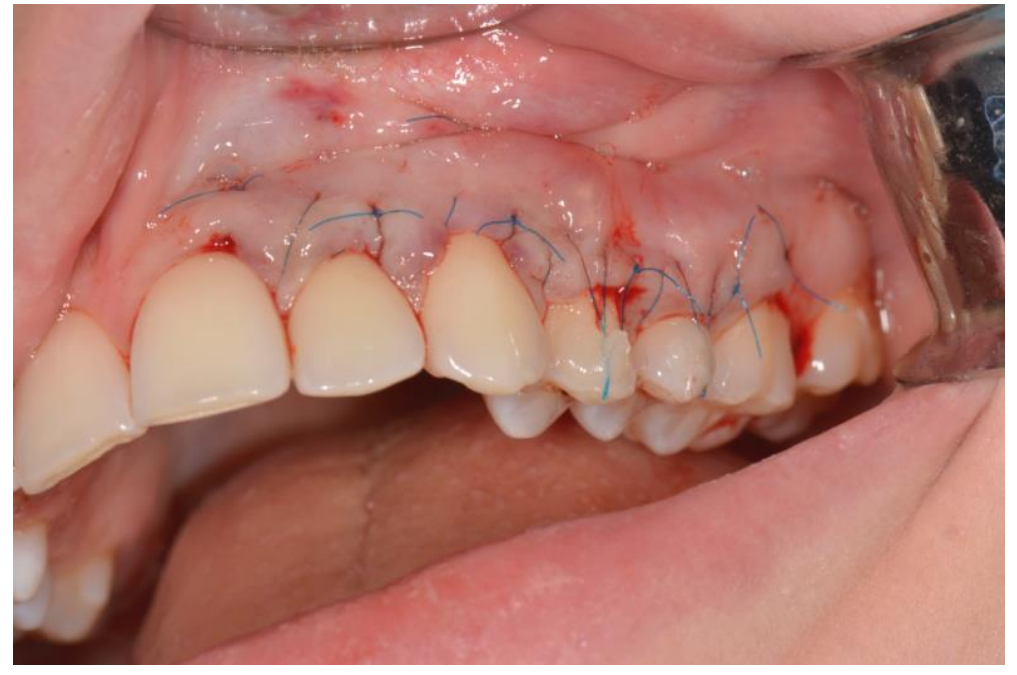

Fig. 15. Type of surgical wound after suturing 


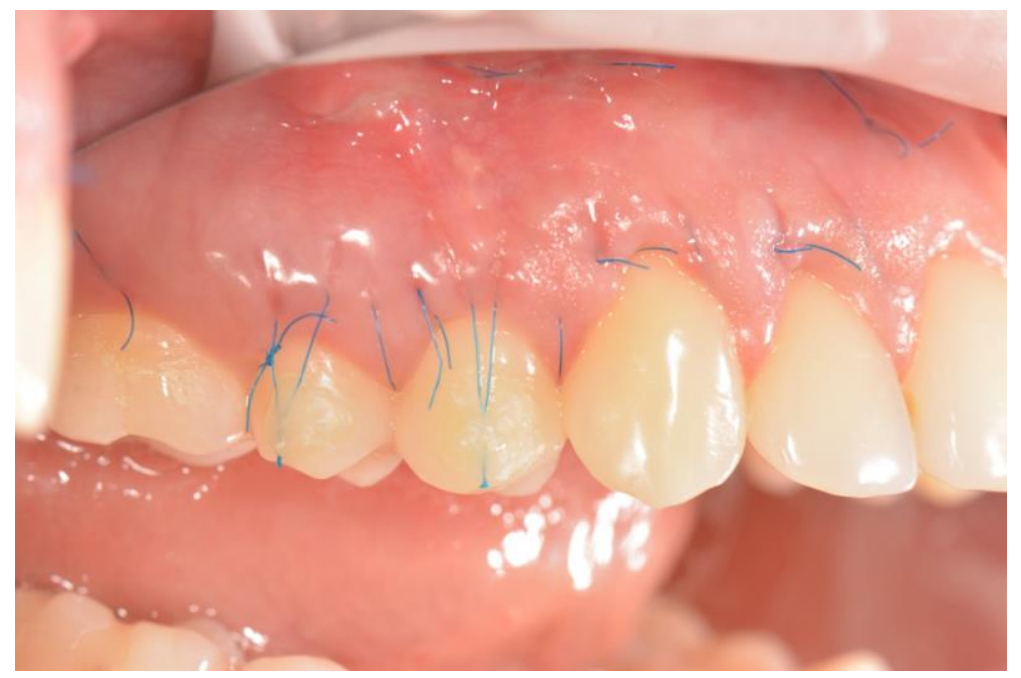

Fig. 16. View of the postoperative wound on the 14th day before the removal of sutures. Complete elimination of gingival recessions

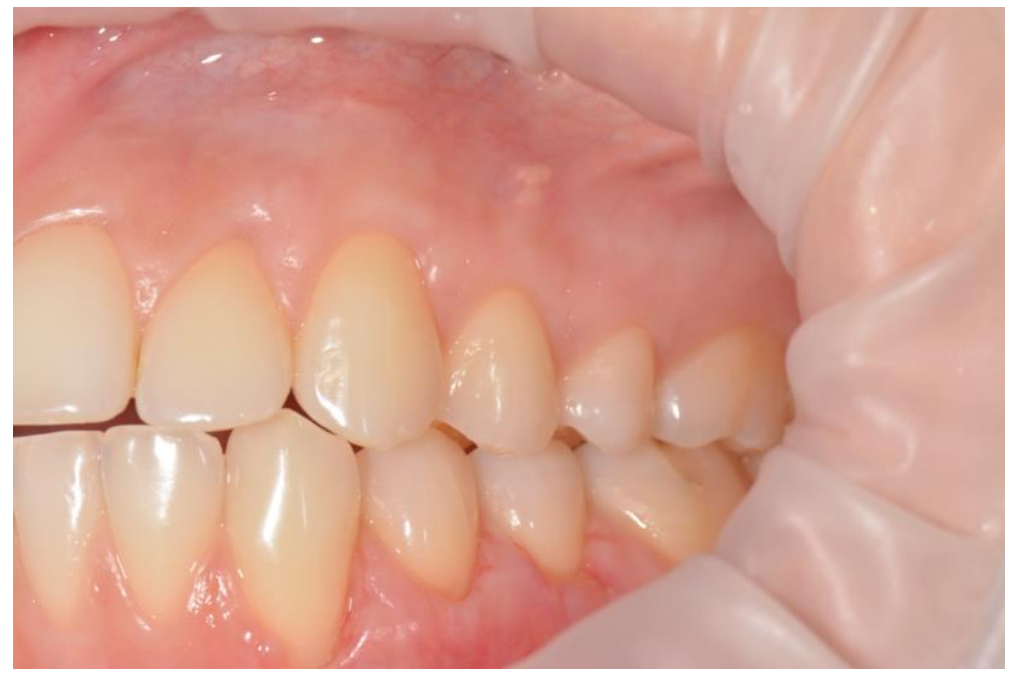

Fig. 17. Result after 3 months. Soft tissues are stable.

\section{Results}

According to the results of the survey and anamnesis, it was determined that $17.2 \%$ of patients smoked, one patient $(4 \%)$ had a lower lip piercing, orthodontic treatment history corresponded to $25.8 \%$ of patients.

In a survey, $83.5 \%$ of patients used medium and high hardness toothbrushes, without changing the degree of hardness of the toothbrushes even in the presence of hyperesthesia of the teeth. $29 \%$ of patients used horizontal movements with a toothbrush when brushing their teeth, $57.5 \%$ of patients used sweeping movements and $13.5 \%$ of patients found it difficult to answer, since their brushing time was less than 30 seconds. 
The main complaints of patients during treatment were the presence of increased tooth sensitivity, aesthetic dissatisfaction, in $15 \%$ of cases, patients noted bleeding when brushing their teeth. In indexing the hygiene and periodontological condition of the oral cavity, the following results were obtained (Table 1):

Table 1. Index assessment of the oral cavity of patients

\begin{tabular}{|c|c|c|}
\hline CPE & OHI-S & PBI \\
\hline $16,6 \pm 0,79$ & $1,79 \pm 0,13$ & $1,34 \pm 0,11$ \\
\hline
\end{tabular}

Supercontacts with central occlusion were observed in $31 \%$ of patients, the presence of abrasion, wedge-shaped defects and restorations in the cervical area of the tooth were noted in $33.4 \%$ of patients.

A comprehensive examination revealed 84 teeth with Miller Class I gingival recession. A generalized form (more than 3 teeth) of gingival recession was noted in $73.4 \%$ of patients, a localized form in $26.6 \%$ of patients. Chronic generalized periodontitis of mild to moderate severity was observed in $26.7 \%$ of patients. A thin gingival biotype corresponded to $60 \%$ of cases, a thick gingival biotype corresponded to $40 \%$ of cases. The thickness of the gingival with a thin biotype was $0.8 \pm 0.94 \mathrm{~mm}$, with a thick biotype $1.2 \pm 0.87 \mathrm{~mm}$. The presence of Miller Class I gingival recession in the area of mucous cords and frenum of lips corresponded to $26.6 \%$ of cases.

In the period from 2019-2020, 11 zones of Miller Class I gingival recession were treated in the presence of a thin biotype, 4 patients in the presence of inflammatory periodontal diseases. The depth of gingival recessions before treatment averaged $2.95 \pm 1.14 \mathrm{~mm}$, and the width of recessions before treatment was $4.02 \pm 0.19 \mathrm{~mm}$.

An analysis of the statistic results of Miller Class I gingival recession treatment by two different surgical methods showed that in each group the results were comparable.

Evaluation of the closure of the gingival recession and the width of the attached keratinized gingiva showed its significant $(p<0.05)$ increase after treatment in both groups of patients, with no significant differences between them.

An analysis of data on the elimination of Miller Class I gingival recession showed an average efficiency of $85 \%$ for $100 \%$ of patients (Table 2).

Table 2. Evaluation of the effectiveness of the closure of gingival recession in patients

\begin{tabular}{|c|c|c|c|c|}
\hline Jaw & $\begin{array}{c}\text { Number of } \\
\text { teeth }\end{array}$ & $\begin{array}{c}\text { Recession } \\
\text { size }\end{array}$ & $\begin{array}{c}\text { Observation } \\
\text { time }\end{array}$ & $\begin{array}{c}\text { The percentage of } \\
\text { gingival recession } \\
\text { closure }\end{array}$ \\
\hline Maxilla & 55 & & $1-3$ month & $99 \%$ \\
\hline Frontal & 42 & $4 \pm 1,2 \mathrm{~mm}$ & & $100 \%$ \\
\hline Lateral & 13 & $3 \pm 0,8 \mathrm{~mm}$ & & $78 \%$ \\
\hline Mandible & 29 & & $1-3 \mathrm{month}$ & $63 \%$ \\
\hline Frontal & 21 & $2,8 \pm 0,3 \mathrm{~mm}$ & & \\
\hline Lateral & 8 & $2,6 \pm 0,4 \mathrm{~mm}$ & & \\
\hline
\end{tabular}

The best clinical results were achieved by eliminating gingival recessions in the frontal part of maxilla, moreover, with a thin and thick biotype, it corresponded to $100 \%$ of the gingival recession closure efficiency.

In 8 patients, a $34 \%$ closure of the gingival recession in the mandible in the lateral region was noted. In cases of surgical treatment of gingival recession of class I according to Miller in patients in the frontal part of mandible, the result corresponded to $78 \%$ of the defect closure efficiency. 


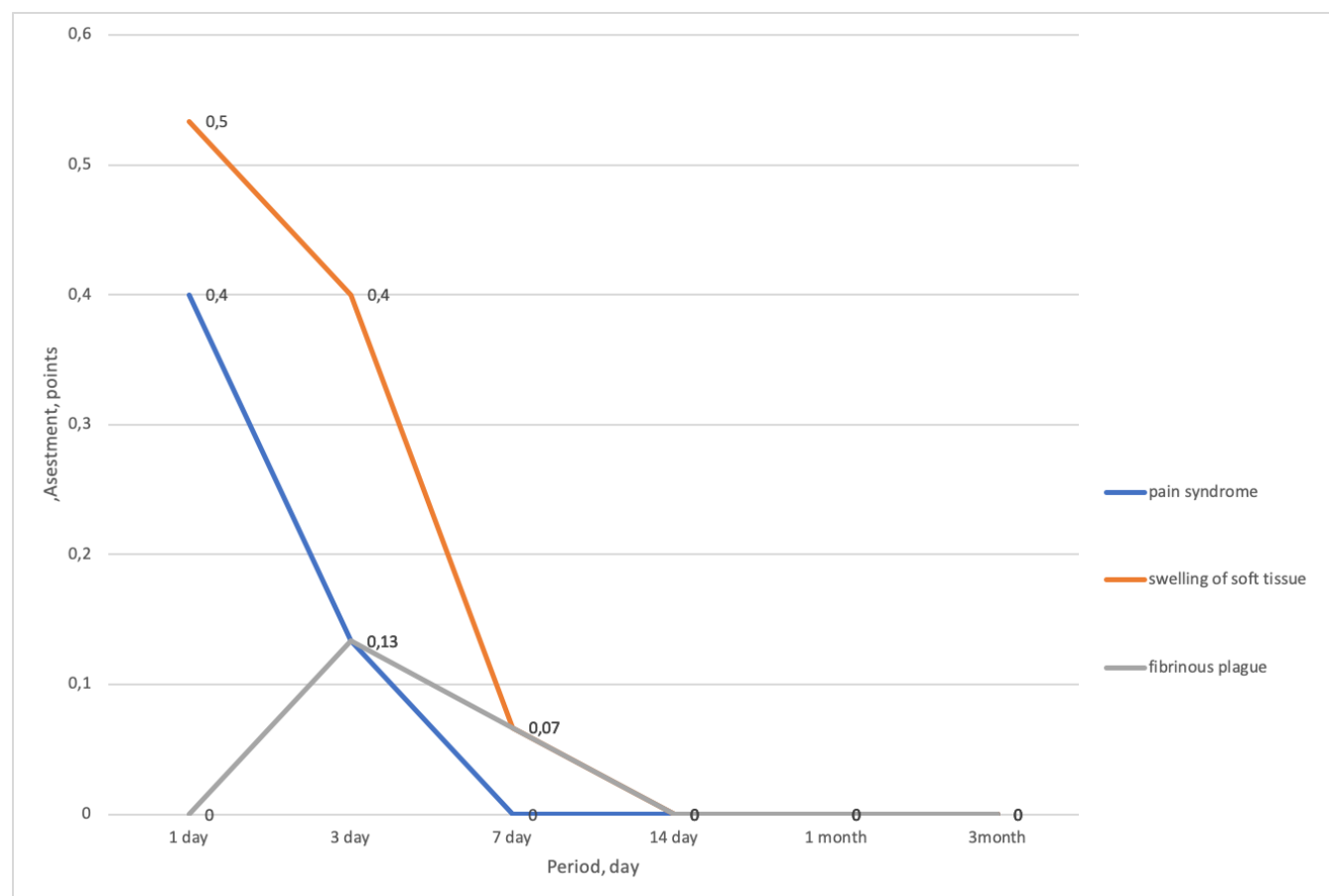

Fig. 18. Evaluation of indicators of pain sensitivity, swelling and consistency of sutures in the postoperative period in patients

In the postoperative period, the highest pain sensitivity indices were observed on the $1^{\text {st }}$ day and corresponded to a value of $0.4 \pm 0.06$ points, which was significantly higher ( $\mathrm{p}$ $<0.05$ ) than the values of the indices on $3^{\text {rd }}, 7^{\text {th }}$ and $14^{\text {th }}$ days (Fig. 18). Swelling of soft tissues in the area of surgical intervention was practically absent, the value of the indicator was $0.5 \pm 0.6$ points for the $1^{\text {st }}$ day and $0.4 \pm 0.5$ points for the $3^{\text {rd }}$ day, reducing its performance by the $7^{\text {th }}$ day ( 0.07 points $)$ to complete absence $(0$ points $)$. The joint consistency was on average low, the maximum value was observed at $3^{\text {rd }}$ day ( 0.13 points), which is not reliable $(\mathrm{p}>0.05)$.

Thus, the severity of pain sensitivity and fibrinous plaque was insignificant in the postoperative period. Postoperative soft tissue swelling was unexpressed for the $1^{\text {st }}$ day and significantly reducing its performance by $3-7$ days to a complete absence.

\section{Conclusion}

The complex use of autogenous platelet plasma and Fibromatrix 3D collagen matrix for the regeneration of soft tissues of the oral cavity is an effective method for treating Miller Class I gingival recession. Using this method makes it possible to obtain stable long-term results. The complex use of autogenous platelet plasma and Fibromatrix 3D collagen matrix for the regeneration of soft tissues of the oral cavity in the treatment of Miller Class I gum recession is an excellent alternative to the use of autogenic connective tissue grafts. 


\section{References}

1. A. Leus, L. Kazeko, Metod. recom. dlya stomatologov parod. cab., 27 (Minsk, MGMI, 1993)

2. G. Zucchelli, Mucogingival Esthetic Surgery (2014)

3. G. Runova, Z. Gugkaeva, Ross.stom., 6, 51 (2011)

4. A. Fevralyova, Ustranenie recissii desny: planirovanie, sovremenniye metody lecheniya, prognoz (2007)

5. N. Tandheelkd, Gingival recessions and orthodontics, 611, 6 (2015)

6. E. Durnovo, N. Bespalova, S. Shashurina, Uspehi sovremennoi nauki, 174, 181 (2016)

7. V.Badalyan, I. Baulin, N. Romanenko, Ross.stom., 4, 32 (2013)

8. A. Fevraliyova, A. Davidyan, Mucogingivalnaya hirurugiya. Problemy I resheniya (PoliMediaPress, 2013)

9. E. Allen, Subpapillary continuous sling suturing method for soft tissue grafting with the tunneling technique, Int. J. Periodontics Restorative Dent., 30(5), 479, 85 (2010)

10. M. McGuide, E. Schever, J. Periodontol., 10, 70 (2014)

11. G. Zucchelli, C. Amore, et al., J. Clin. Periodontol., 10, 70 (2003)

12. L. Orehova, R. Farkhshatova, L. Gerasimova et al., Med.Vestnik Bashkortostana, 5, 35 (2019)

13. E. Vaicner, Dental Forum, 3, 87 (2012)

14. R. Ahmerov, R. Zarudiy et al., Autostimulyaciya regenativnyh processov v chelustnolicevoi hirurgii I kosmetologii (Metod.posobie, 2011)

15. V. Sarkisyan, O. Zaratyanc, A. Panin et al., Parodontologiya, 62, 26 (2012)

16. E. Kogina, L. Gerasimova, et al., Clinic.Stom., 3, 13 (2018) 